\title{
Ultrasonographic and imaging appearance of peripheral intraneural vascular anomalies: report of two cases and review of the literature
}

\author{
Georgeta Mihaela Rusu', Constantin Ciuce ${ }^{2}$, Lucian Fodor ${ }^{3}$, Simona Manole ${ }^{1}$, \\ Sorin Marian Dudea ${ }^{1}$
}

${ }^{1}$ Radiology Department, "Iuliu Hatieganu" University of Medicine and Pharmacy, ${ }^{2} 1$ st Surgical Department, "Iuliu Hatieganu" University of Medicine and Pharmacy, ${ }^{3}$ Division of Plastic and Reconstructive Surgery, Emergency Clinical County Hospital, Cluj-Napoca, Romania

\begin{abstract}
The purpose of the paper is to present the ultrasonographic and imaging appearance of two cases of peripheral nerve intraneural vascular anomalies and provide a comprehensive review of the publications on this subject. The clinical presentation, ultrasonographic appearance, corresponding imaging and outcome of a case of ulnar nerve venous malformation and a case of median nerve arteriovenous malformation are presented.

A literature search revealed 35 papers presenting 52 cases of vascular anomalies involving the peripheral nerves. The ultrasonographic appearance was described only in ten cases. Our review suggests that peripheral intraneural vascular anomalies are twice more frequent in women. About three quarters of them are located in the upper limb, with the median nerve involved in one third and the ulnar nerved involved in a quarter of all cases. Most of the cases are hemangiomas. Peripheral neural compartment syndromes in patients with coexisting vascular anomalies may prompt for vascular neural involvement, requiring diagnostic imaging studies. Gray-scale and Doppler ultrasound are the methods of first choice, as they provide not only direct visual proof of neural involvement but also contribute to the differential diagnosis between hemangiomas and vascular malformations.
\end{abstract}

Keywords: ultrasonography; peripheral nerves; vascular malformations; hemangioma

\section{Introduction}

Vascular anomalies, defined as aberrations that appear during vascular development, are rather common, may involve any anatomical structure and have a prevalence of up to $4.5 \%$ in the general population, being diagnosed mainly during childhood [1]. However, vascular anomalies involving the peripheral nervous system are extremely rare, with a limited number of cases reported.

For a long time, some confusion persisted in defining this group of anomalies, due to ambiguous terminol-

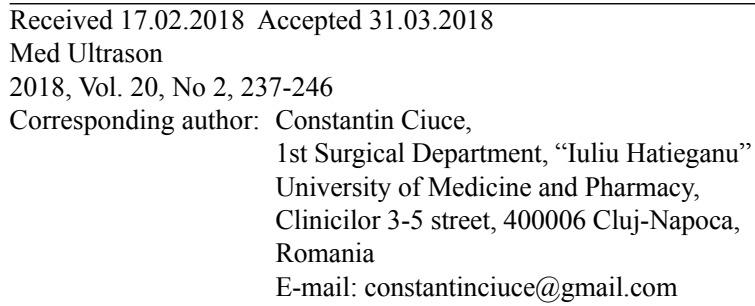

E-mail: constantinciuce@gmail.com

ogy and, therefore, interdisciplinary discordance. The biologic classification introduced in 1996 and thereafter developed by ISSVA (International Society for the Study of Vascular Anomalies) [2], clarifies the class division of this type of lesions according to their clinical behavior and cellular characteristics. Thus, two categories are described: proliferative lesions (hemangiomas) and malformations - simple or complex -, each of the classes having a distinctive pattern of development.

The aim of the current paper is to present two cases of vascular anomalies involving peripheral nerves of the upper limb, highlighting the ultrasonographic and imaging appearance and to provide a systematic review of the imaging appearance of this rare type of lesions.

\section{Case report 1}

A 47-year-old female patient with known left-sided upper limb venous malformation, obvious at birth, pre- 


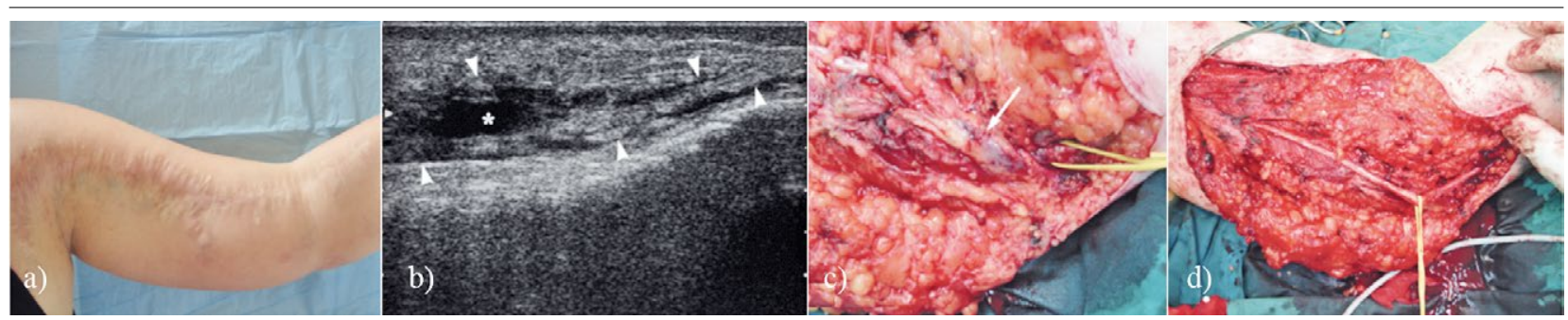

Fig 1. a) Clinical appearance of patient no.1: multiple pale blue subcutaneous lesions are visible along the scar; b) Ultrasound of the ulnar nerve (arrowheads), longitudinal scan along the arm. Vascular engorgement of the nerve in marked by *; c) and d) Intraoperative appearance of the ulnar nerve: venous engorgement of the nerve, showing pathologic correspondence to figure $1 \mathrm{~b}$ and post resection appearance.

sented for symptoms of pain and paresthesia in the palm and the IVth and Vth fingers as well as decreased ability to catch and especially to retain objects. The long-lasting symptomatology started at the age of 6 in the context of a trauma and became more conspicuous in adolescence in the circumstances of hormonal changes. Previous surgery of the arm was noted but operative protocols were unavailable.

The clinical examination revealed multiple subdermal pale blue lesions of the inner side of the left arm, along the scar of previous surgery (fig 1a). The lesions were soft, easily compressible on palpation, characterized by volume increase when the limb was in dependent position. The prehensile function of the left hand was impaired, especially on the ulnar territory. The diagnostic suspicion of a venous malformation involving the skin and, possibly, the left arm muscle layers associated with cubital tunnel syndrome was raised. An ultrasound exam was requested, to define the in depth extent of the vascular changes and to analyze the ulnar nerve status in the canal.

On ultrasound, multiple sinuous vascular tracts, located both subcutaneously and in the intermuscular planes of the inner left arm were seen. The diameter and area of the ulnar nerve in the canal were within normal limits. Several anechoic, serpentine, vascular structures that almost completely replaced the nerve structure and were collapsible at transducer compression were evidenced along the course of the ulnar nerve in the arm (fig 1b). On Doppler, these vessels exhibited slow, single-phase, venous flow.

Intraoperatively, the diagnosis of venous malformation with stalk involvement of the left ulnar nerve was confirmed. The patient underwent surgical exploration with neurolysis and vascular malformation ligation (fig 1c).

\section{Case report 2}

A 42-year-old female patient, known with a congenital right palmary arteriovenous fistula with several pre- vious surgical interventions was admitted to the surgery department, complaining of pain and paresthesia in the thenar eminence of the right hand, respectively at the level of the thumb and index.

Clinically, multiple dilatations of the radial and ulnar superficial arterial branches in the distal third of the right forearm were noticed. Also, engorged arterial palmar branches were apparent as well as dilated dorsal and palmar digital veins, extending to the ulnar, radial and cephalic veins (fig 2a). The ultrasound examination was requested to assess the carpal tunnel syndrome and to locate the arteriovenous communication nidus.

On Doppler ultrasound three arteriovenous fistula foci were detected, all located in the palmar side of the hand, in the thenar, hypothenar and mid-palm areas, respectively. The median nerve, within the carpal tunnel, appeared thick, hypoechoic, slightly depressible, with a marked dotted appearance (fig 2b). On color Doppler, the whole nerve was colored, containing arterial signal with high velocity and low impedance (fig $2 \mathrm{c}$ ). Tracking the nerve upstream revealed intraneural arterial vessels up to the middle of the forearm (fig 2d). Pulsed wave Doppler sampling revealed high velocity low resistance intraneural flow (fig 2e). The ulnar nerve had a normal appearance. Computed tomography (CT) angiography (CTA) and Magnetic Resonance (MR) angiography (MRA) were requested for three-dimensional mapping of the vascular changes in order to establish the treatment strategy.

Non-enhanced CT of the upper right limb revealed multiple calcifications, located in the lower third of the forearm and in the palmar region. Numerous dilated, sinuous vascular channels were seen, located both deeply, between the muscular layers of the flexors and subcutaneously. Post contrast, in the arterial phase, in addition to enhancement of the radial and ulnar arteries, multiple tortuous vascular tracts were revealed, especially in the distal third of the forearm and the lateral three thirds of the palm. Early venous enhancement was also noted. Abnormal vascular channels were present in the anatomical area of the median nerve (fig $2 \mathrm{f}-\mathrm{i}$ ). 


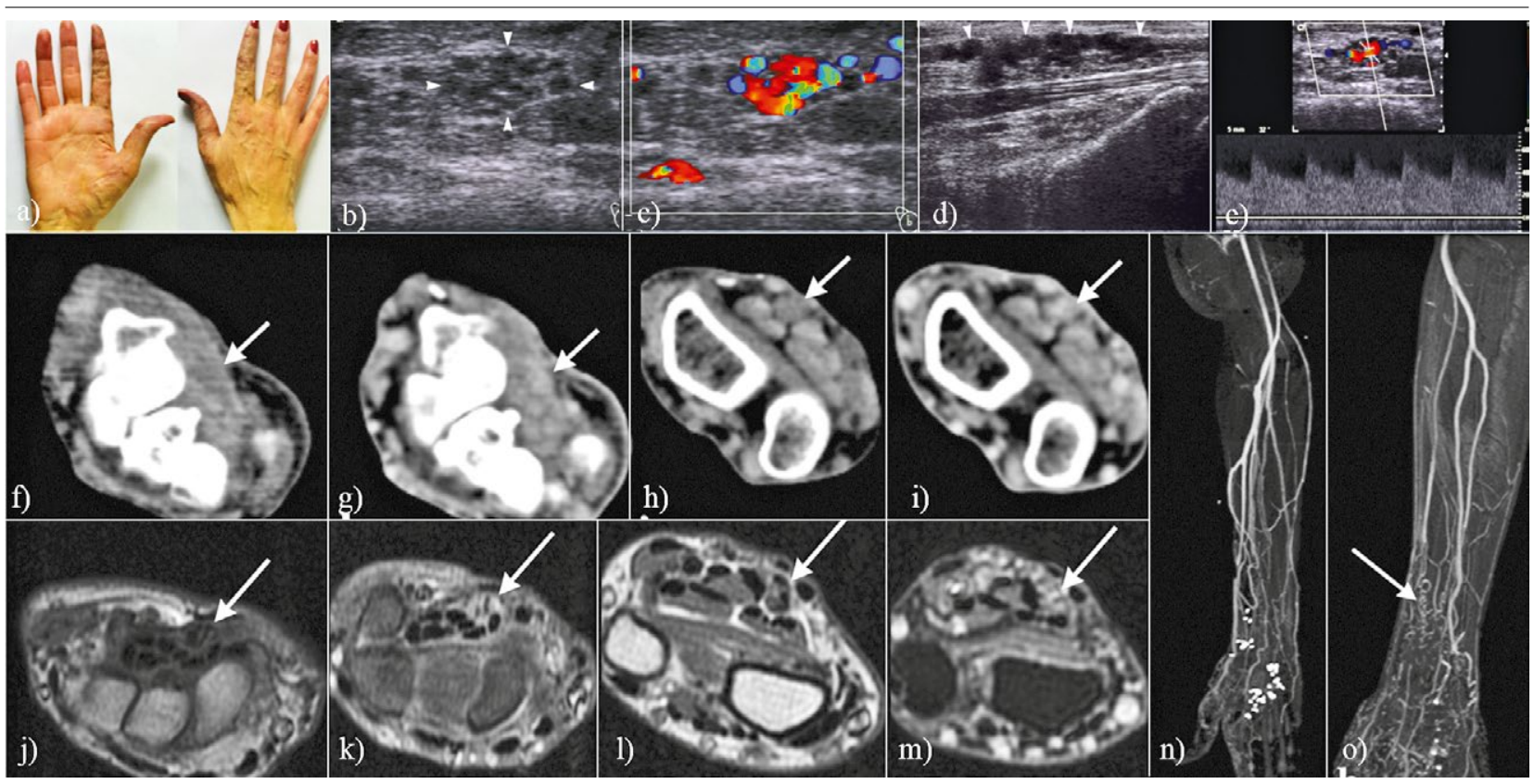

Fig 2. a) Clinical appearance of patient no. 2: prominent vascular structures are seen on both sides of the right hand and wrist; notice the blue discoloration of the pulp of the index and the thumb; Ultrasonography of the right forearm: b) the median nerve (arrowheads) within the carpal tunnel appears enlarged, hypoechoic and shows marked dotted appearance; c) on color Doppler, the whole nerve surface is occupied by high flow vascular channels; d) tracking the nerve upstream reveals multiple intraneural vascular channels (arrowheads); e) pulsed wave Doppler interrogation of the nerve reveals high velocity low resistance arterial flow, compatible with arterio-venous fistula feeders; CT scan of the carpal tunnel (f,g) and of the forearm (h,i); Nonenhanced (f,h) and arterial phase images (g,i). Enhancement in the anatomic area of the median nerve (arrows) is noted on postcontrast images. Multiple abnormal vascular channels are also noted on the contrast enhanced images; MR scan of the carpal tunnel $(\mathrm{j}, \mathrm{k})$ and of the forearm $(1, \mathrm{~m})$. Nonenhanced T1 Fast spin echo sequence $(\mathrm{j}, \mathrm{l})$ and T1 RHO Fat Sat contrast enhanced images $(\mathrm{k}, \mathrm{m})$. Enhancement in the anatomic area of the median nerve (arrows) is noted on postcontrast images. Multiple abnormal vascular channels are also noted on the contrast enhanced images; CT angiography (CTA) (n) and MR angiography (MRA) (o): tortuous, rapidly enhanced arterial vessels, with an important venous component are seen with both methods; numerous phlebolyths are visible on the CTA examination. MRA depicts tortuous vessels along the course of the median nerve (arrow).

The morphological MRI examination using the T1 FSE, GRE and T2 FSEsequences revealed multiple tortuous vascular tracts with increased diameter, located in the lower third of the right forearm and in the palmar region, between the muscular and tendinous layers, but also subcutaneously, with signal void areas especially on the ventral side. These vessels were located on the anatomical course of the median nerve, in its distal third and in the carpal tunnel, as well as along its palm branches, extending up to the level of the thumb and index (both on the palmar and on the dorsal side) (fig 2j-m). On contrast enhanced CTA and MRA (see image caption). there was a rapid filling of these vessels with enhancement persistence in the venous phase (fig $2 n, 0$ ).

The extensive involvement of the median nerve induced a major change in the treatment plan: the palmar arteriovenous fistulae were suppressed, but a conservative attitude was employed towards the forearm vascular lesions.

The patient returned after 5 years with altered symptoms, complaining of paresthesia, pain and loss of the thermal sensitivity in the IVth and Vth fingers of the right

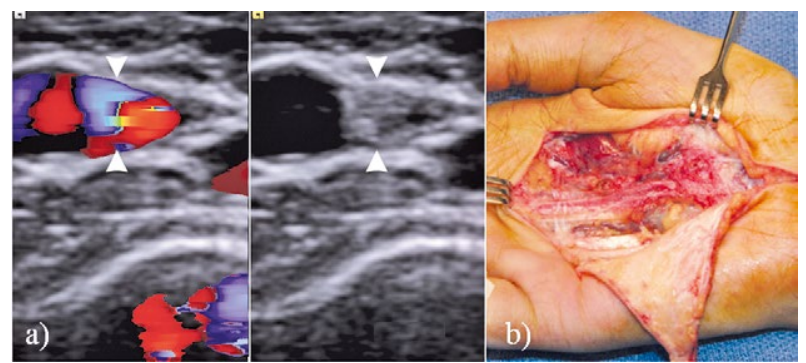

Fig 3. a) Color Doppler of the right ulnar nerve (arrowheads) showing the same type of changes as seen within the median nerve; b) Intraoperative appearance: multiple dilated vessels as a consequence of arteriovenous fistulas appear in both the thenar and the hypothenar areas. A saccular aneurysm of the ulnar artery is also noted.

hand. On ultrasound the appearance of the median nerve was unaltered, but changes of the same type - hypoechogenic neural thickening, tortuous vessels, high velocity arterial flow with low impedance - were noted in the distal $5 \mathrm{~cm}$ of the ulnar nerve (fig $3 \mathrm{a}$ ). 
At surgery, ligation and cauterization of many dilated palmar vessels was performed. A superficial branch of the radial nerve, covered by veins and dilated capillaries at the level of the epineurium (fig $3 b$ ) was severed respectively cauterized, with consecutive neurorrhaphy. The clinical-imaging and intraoperative report of arteriovenous malformation was confirmed by histopathology.

\section{Literature review}

\section{Research methods}

To comprehensively review the current literature, we electronically retrieved all studies that reported intraneural vascular anomalies from Medline (PubMed), Cochrane Library and Scopus electronic databases. The search was carried out between June 20 - 26th, 2017. The following free text search terms were used in "All fields": peripheral nerve or intraneural and vascular anomaly or vascular malformation or arteriovenous malformation or venous malformation or hemangioma.

The search was restricted to English language papers published in the last 40 years, on human subjects. The bibliographies of the selected studies were further searched for additional references of relevance. Any prospective or retrospective study but also case reports, editorials, reviews and studies on pediatric population were included. All data were consolidated onto a standardized form. The primary data extracted from each article included age and gender of the patient, involved nerve, imaging studies performed and final diagnosis. Detailed description of the imaging appearance was recorded, whenever available.

For the MR studies, the following supplemental data were recorded: appearance of a mass, boundaries, ho- mogeneity, the T1 and T2 aspect, the presence of intravascular intralesional signal void, postgadolinium type of enhancement, intensity, persistence, and evidence of drainage vessels.

For the ultrasonographic appearance, the supplemental data recorded were: presence of mass, delineation, echotexture/echogenicity, presence of vessels inside the nerve on Doppler studies, flow velocity and type of vascular signal (arterial/venous), imaging diagnosis and histopathological diagnosis.

\section{Results}

We found 35 English language papers published in the last 40 years, presenting 52 cases of vascular anomalies involving the peripheral nerves (Table I). To this collection we added the two cases described in this paper, leading to a total of 54 cases.

Gender distribution. Three papers [8,19,33] reported a total of 9 cases presenting only the afflicted nerve and the histopathological diagnosis, without supplemental data. In these cases patient gender was labeled NA (not available) and they were not included in the calculation. For the remaining 45 cases, the female/ male ratio of the prevalence of intraneural vascular anomalies was $2: 1$.

Location. In the reviewed articles, 40 cases $(74.07 \%)$ presented lesions of the upper limbs. The median nerve was involved in 20 cases $(37.04 \%$ al all cases and 50\% of the upper limb cases), the ulnar nerve in 13 cases $(24.07 \%$, respectively $32.5 \%)$ and digital branches of the median, radial and ulnar nerves in 6 cases $(11.11 \%$ respectively $15 \%$ ). There was one case of brachial plexus involvement. One of the cases with ulnar nerve involve-

Table I. Review of English literature on vascular anomalies of the peripheral nerves, based on gender distribution, lesion location, employed imaging techniques and histopathological diagnosis.

\begin{tabular}{|c|c|c|c|c|}
\hline Authors/ Year & $\begin{array}{l}\text { Age/gender of } \\
\text { the patient }\end{array}$ & Nerve & Imaging & Final Diagnosis \\
\hline Kojima et al1976 [3] & $19 / \mathrm{F}$ & Median & NA & Hemangioma \\
\hline Chopra et al 1979 [4] & $45 / \mathrm{M}$ & Median & Arteriogram & Arterio-Venous Fistula \\
\hline Wood $1980[5]$ & $13 / \mathrm{F}$ & Peroneal & NA & Intraneural Hemangioma \\
\hline Peled et al 1980 [6] & $19 / \mathrm{F}$ & Median & X-ray & Cavernous hemangioma \\
\hline Kon et al 1981 [7] & $8 / \mathrm{F}$ & $\begin{array}{l}\text { Radial digital + } \\
\text { Ulnar digital }\end{array}$ & NA & $\begin{array}{l}\text { Extraneural Benign Cavern- } \\
\text { ous Hemangioma + Benign } \\
\text { Intraneural Hemangioma }\end{array}$ \\
\hline Louis et al 1985 [8] & NA & Ulnar & NA & Intraneural hemangioma \\
\hline \multirow[t]{2}{*}{ Patel et al 1986 [9] } & $13 / \mathrm{F}$ & Median & Arteriogram & Intraneural hemangioma \\
\hline & $18 / \mathrm{F}$ & Median & Arteriogram & Intraneural hemangioma \\
\hline Prosser et al 1987 [10] & $38 / \mathrm{F}$ & Median & NA & Cavernous hemangioma \\
\hline Bilge et al 1989 [11] & $10 / \mathrm{M}$ & Peroneal & NA & Hemangioma \\
\hline Nagay et al 1990 [12] & $22 / \mathrm{F}$ & Digital & X-ray & Cavernous hemangioma \\
\hline
\end{tabular}




\begin{tabular}{|c|c|c|c|c|}
\hline Feyerabend et al 1990 [13] & $20 / \mathrm{F}$ & Median & $\mathrm{CT}$ & Hemangioma \\
\hline Mestdagh et al 1990 [14] & $23 / \mathrm{F}$ & Posterior tibial & X-ray & Endoneural hemangioma \\
\hline Coessens et al 1991 [15] & $12 / \mathrm{M}$ & Median & DSA & Intraneural hemangioma \\
\hline Kline et al 1992 [16] & $63 / \mathrm{M}$ & Ulnar & X-ray & Hemangioma \\
\hline Konet al 1993 [17] & $57 / \mathrm{M}$ & Ulnar & NA & Cavernous hemangioma \\
\hline Ergin et al 1998 [18] & $\mathrm{NA} / \mathrm{F}$ & Median & Angiogram, CT, MRI & Hemangioma \\
\hline \multirow[t]{7}{*}{ Kim et al 2005 [19] } & NA & Median & Angiogram, CT and/ & Venous angioma \\
\hline & NA & Ulnar & or MRI & Hemangioma \\
\hline & NA & Ulnar & & Hemangioma \\
\hline & NA & Sciatic & & Venous angioma \\
\hline & NA & Femoral & & Venous angioma \\
\hline & NA & Tibial & & Venous angioma \\
\hline & NA & Peroneal & & Hemangioma \\
\hline Kerimoglu et al 2006 [20] & $9 / \mathrm{F}$ & Digital & X-ray, MRI & Hemangioma \\
\hline Galea et al 2007 [21] & $23 / \mathrm{M}$ & Ulnar digital & US Doppler, DSA & Vascular malformation \\
\hline Châtillon et al 2007 [22] & $40 / \mathrm{F}$ & $\begin{array}{l}\text { Inferior trunk of brachial } \\
\text { plexus }\end{array}$ & MRI, DSA & Hemangioma \\
\hline $\begin{array}{l}\text { Papagelopoulos et al } 2008 \\
\text { [23] }\end{array}$ & $56 / \mathrm{F}$ & Median & $\begin{array}{l}\text { X-ray, US+ Doppler, } \\
\text { MRI, CT, MRA, DSA }\end{array}$ & Intraneural hemangioma \\
\hline Doğramacı et al 2008 [24] & $14 / \mathrm{F}$ & Median & X-ray, US, MRI & Hemangioma \\
\hline Vekris et al 2008 [25] & $10 / \mathrm{F}$ & Median & US, MRI & Intrinsic hemangioma \\
\hline Kim et al 2010 [26] & $47 / \mathrm{M}$ & Ulnar & X-ray, US & Hemangiomas \\
\hline \multirow[t]{4}{*}{ Gompel et al 2010 [27] } & $23 / \mathrm{M}$ & Sciatic + Tibial + Peroneal & MRI & $\begin{array}{l}\text { Mixed venous and cavernous } \\
\text { angioma within epineurium }\end{array}$ \\
\hline & $33 / \mathrm{F}$ & Sciatic + Tibial + Peroneal & MRI & Arterio-Venous Malformation \\
\hline & $36 / \mathrm{M}$ & Sciatic & MRI & Venous malformation \\
\hline & $18 / \mathrm{F}$ & Sciatic & MRI & Capillary hemangioma \\
\hline Hariri et al 2011 [28] & $34 / \mathrm{M}$ & Median & MRI & Venous malformation \\
\hline Duzgun et al 2013 [29] & $12 / \mathrm{M}$ & Radial digital & MRI & Intraneural hemangioma \\
\hline Reddy et al 2013 [30] & $18 / \mathrm{M}$ & Median & HRUS, MRI & Capillary hemangioma \\
\hline \multirow[t]{8}{*}{ Prasad et al 2015 [31] } & $13 / \mathrm{M}$ & Ulnar & MRI & Hemangioma \\
\hline & $18 / \mathrm{F}$ & Ulnar & MRI & Hemangioma \\
\hline & $10 / \mathrm{F}$ & Ulnar & MRI & $\begin{array}{l}\text { Vascular malformation (ex- } \\
\text { traneural component) }\end{array}$ \\
\hline & $38 / \mathrm{F}$ & Median & MRI & NA \\
\hline & $25 / \mathrm{F}$ & Ulnar digital & MRI & Hemangioma \\
\hline & $43 / \mathrm{F}$ & Sciatic & MRI & NA \\
\hline & $18 / \mathrm{F}$ & Sciatic & MRI & Hemangioma \\
\hline & $33 / \mathrm{F}$ & Sciatic & MRI & Vascular malformation \\
\hline Rousieet al 2015 [32] & $32 / \mathrm{M}$ & Median & MRI & Capillary hemangioma \\
\hline Prasad et al 2015 [33] & NA & Ulnar & MRI & Hemangioma \\
\hline Jafari et al 2015 [34] & $40 / \mathrm{F}$ & Ulnar & $\begin{array}{l}\text { X-ray, US+ Doppler, } \\
\text { MRI }\end{array}$ & Cavernous hemangioma \\
\hline $\begin{array}{l}\text { González Porto et al } 2016 \\
\text { [35] }\end{array}$ & $2 / \mathrm{M}$ & Median & US Doppler, MRI & Venous Malformation \\
\hline Prater et al 2017 [36] & $18 / \mathrm{F}$ & Ulnar & MRI & $\begin{array}{l}\text { Intraneural mixed lym- } \\
\text { phangioma and cavernous } \\
\text { hemangioma }\end{array}$ \\
\hline Al-Garnaweeet al 2017 [37] & $43 / \mathrm{F}$ & Median & MRI & Cavernous hemangioma \\
\hline Our case no $1 / 2018$ & $47 / \mathrm{F}$ & Ulnar & US+ Doppler & Venous Malformation \\
\hline Our case no $2 / 2018$ & $38 / \mathrm{F}$ & Median & $\begin{array}{l}\text { US+ Doppler, CT, } \\
\text { CTA, MRI, MRA }\end{array}$ & Arterio-Venous Malformation \\
\hline
\end{tabular}

NA - not available: US - ultrasonography; HRUS - high resolution ultrasonography; MRI - magnetic resonance imaging; MRA - magnetic resonance angiography; CT - computed tomography; CTA - computed tomography angiography; DSA - digital substraction angiography 
ment presented intraneural hemangiomas with double localization, at a distance from each other, one located at the elbow and the other one in the carpal region.

There were 14 cases $(25.95 \%)$ of lower limb lesions. The sciatic nerve was involved in 6 cases $(11.11 \%$ of the total cases, $45.8 \%$ in the lower limb), the peroneal nerve in 3 cases $(5.55 \%$, respectively $21.4 \%)$ and the tibial nerve in 2 cases ( $3.70 \%$ respectively $14.28 \%$ ). There was one case of femoral nerve involvement and two cases of vascular abnormalities with multiple localization affecting the sciatic (distal), tibial and peroneal nerves (in their proximal parts).

\section{Pathology}

For 30 cases $(55.55 \%)$ the final diagnosis was hemangioma, based on histopathological analysis. Of these tumors, 24 were located at the level of upper limb, affecting the median nerve (11 cases) $[3,9,13,15,18,23$ $25,30,32]$, ulnar nerve ( 8 cases) $[8,16,19,26,31,33]$, digital branches of ulnar and radial nerves (4 cases) $[7,20,29,31]$ and the inferior trunk of brachial plexus (1 case) [22]. The other 6 tumors were located at the level of lower limb, involving the sciatic nerve (2 cases) [27,31], peroneal nerve (3 cases) $[5,11,19]$ and posterior tibial nerve ( 1 case) [14]. These lesions were named differently by the authors: hemangioma $[3,11,13,16,18$ $20,22,24,26,31,33]$, intraneural hemangiomas [5,7$9,15,23,29]$, endoneural hemangioma, intrinsic hemangioma [25] or capillary hemangioma [27,30,32]. Konet al [7] described one case in which the coexistence of an intraneural hemangioma and an extraneural cavernous hemangioma at the level of the digital branches of the ulnar nerve was observed. Prateret al [36] reported one case of mixed neoplastic pathology: intraneural hemangioma and lymphangioma.

The term cavernous hemangioma was used for 6 cases (11.11\% of all cases), although, according to the ISSVA classification $[1,38,39]$, when these lesions are described in adulthood, they fall into the group of slow flow venous malformations.

There were six cases of venous angiomas (VA) (11.11\%) of which one case was described as mixed venous and cavernous angioma developed at the epineurial level, involving the sciatic nerve in its distal portion as well as the tibial and peroneal nerves in their proximal part [27].

In four cases $(7.4 \%)$, the diagnosis was venous malformation (VM).

Of the fast-flow malformations, there were two cases of arteriovenous malformation (AVM) and one case of arteriovenous fistula (AVF).

The term "vascular malformation" without specifying its nature, was used in 3 of the reviewed cases [21,31].
For two cases, the authors [31] provide no information on the final diagnosis, therefore we labeled these cases with NA (not available).

\section{Systematic analysis of the imaging appearance of vascular anomalies involving peripheral nerves}

Radiography. This method seems useless in the assessment of peripheral nerve vascular lesions. Of the 54 reported cases, it was performed only in 10 , with 7 normal results. In three cases - two hemangiomas $[6,23]$ and one arteriovenous malformation (our case no.2), phlebolyths or soft tissue calcifications were described and in only one case [6] a soft tissue mass was seen.

Angiography (arteriography, digital subtraction angiography) was used in 15 of the reported cases, either for diagnostic purposes (detailed anatomical location, upstream or downstream vessel identification), or as a precursor of surgical resection, as guidance for embolization and sclerotherapy. With the exception of 2 cases of hemangioma [9] where no abnormal aspect was described, in all other 13 cases ( 9 hemangiomas and 4 venous angiomas), the feeders and draining vessels of the lesion were highlighted.

Hemangiomas appeared as well-circumscribed masses, represented by a tissue component, surrounded by dilated arteries and drainage veins, sometimes with varicose aspect [15]. The phlebolyths induced small contrast filling defects [23].

The venous malformations were characterized by the appearance of either a vessel or dilated string of vessels (phlebectasia) or by spongiform channels and abutting calcifications, with evidence of venous drainage in a late phase [40].

Computed tomography was used in the diagnosis of 11 cases of peripheral nerve vascular abnormalities. CTA highlighted prominent vascularization and defined lesion limits [41]. Feyerabend et al [13] presented three cases of peripheral nerve tumors explored exclusively by CT, one of which was a hemangioma with the aspect of well defined tumor, lacunar appearance and fast and transient enhancement.

Magnetic Resonance Imaging was used in 34 of the 54 cases. Both native and post-contrast sequences, such as magnetic resonance angiography (MRA) and TRICKS-MRA (Multi-Phase Contrast Kinetics-MR Angiography), allow the visualization of the vascular component, the feeder sand drainage channels $[40,42]$.

Hemangiomas (17 cases) appear as tissue masses with hypo- or isosignal on T1 weighted sequences and T2 hypersignal, well delineated, with signal void due to multiple vessels, presenting early and heterogeneous enhancement after gadolinium [20,22-25,27, 29,30-33]. 
Arteriovenous malformations ( 2 cases, including our case no. 2) appear as poorly delineated vascular lesions with no tissue component, early enhancement, direct visualization of the arteriovenous communication and early venous uptake, before the venous phase [27].

Venous malformations ( 3 cases) appear as heterogeneous non-tissular lesions with $\mathrm{T} 1$ intermediate signal and T2 hyper-signal, with contrast uptake in the solid components of the lesion $[27,35]$.

\section{Ultrasonography of vascular anomalies involving peripheral nerves}

Gray scale and Doppler ultrasound were used as diagnostic techniques in only 10 of the reported cases (Table II).

Hemangiomas (6 cases) appeared as solid structures with sharp delineation and heterogeneous echostructure. Arterial and venous intralesional signal was recorded on Doppler scans.

AVM (2 patients, one of which is described in the present paper) is characterized by the vascular "clew" appearance without obvious tissue components, with the presence of a nidus and neighboring calcifications. On
Doppler, the arteriovenous shunt becomes obvious, with low resistance arterial waveforms in the feeders and arterialization of the venous drainage.

The ultrasonographic appearance of the VM (2 patients, one of which is presented in this paper) may be variable, depending on the type: phlebectasia or varicose dilation, multiple, tortuous, dilated veins, grouped or bearing spongiform configuration, with fluid filled spaces but no tissue component. On Doppler, no flow or slow venous flow is recorded. Chronic thrombi results in phlebolyth formation, observed in $9-27 \%$ of all VM, studied with US [41].

No specific information could be retrieved regarding the US appearance of intraneural cavernous hemangioma or venous angioma.

According to our review, the current imaging techniques commonly used, US (high resolution gray scale US, Doppler) and MRI, demonstrated a close relation between the nerve path and the vascular anomaly, accurately indicating the diagnosis in 22 cases [23,26-35,37]. Also, we found a single case in which postoperative histopathological examination confirmed the imaging diagnosis of hemangioma, established exclusively by using computed tomography [13].

Table II. Systematic analysis of the ultrasonographic appearance of vascular anomalies involving peripheral nerves and the correlation between imaging and histopathological diagnosis.

\begin{tabular}{|c|c|c|c|c|c|c|c|c|}
\hline \multirow[t]{2}{*}{ Author/ Year } & \multirow{2}{*}{$\begin{array}{l}\text { Imaging Diag- } \\
\text { nosis }\end{array}$} & \multirow{2}{*}{$\begin{array}{l}\text { Histopatho- } \\
\text { logical Diag- } \\
\text { nosis }\end{array}$} & \multicolumn{3}{|l|}{ US 2D } & \multicolumn{3}{|l|}{ Doppler US } \\
\hline & & & Mass & Demarcation & $\begin{array}{l}\text { Echotexture/ } \\
\text { Echogenicity }\end{array}$ & $\begin{array}{l}\text { Vasculari- } \\
\text { zation in } \\
\text { the nerve }\end{array}$ & $\begin{array}{l}\text { Flow } \\
\text { velocity }\end{array}$ & $\begin{array}{l}\text { A/V } \\
\text { Signal }\end{array}$ \\
\hline $\begin{array}{l}\text { Galea et al } 2007 \\
{[21]}\end{array}$ & AVM & NA & NA & NA & NA & Yes & Normal & Yes \\
\hline $\begin{array}{l}\text { Papagelopoulos } \\
\text { et al 2008 [23] }\end{array}$ & NA & $\begin{array}{l}\text { Intraneural } \\
\text { hemangioma }\end{array}$ & Yes & Well-defined & $\begin{array}{l}\text { Heterogene- } \\
\text { ous }\end{array}$ & Moderate & NA & NA \\
\hline $\begin{array}{l}\text { Doğramaci et al } \\
2008 \text { [24] }\end{array}$ & Ovoid Mass & Hemangioma & Yes & NA & $\begin{array}{l}\text { Hypo-echoic/ } \\
\text { Cystic }\end{array}$ & NA & NA & NA \\
\hline $\begin{array}{l}\text { Vekris et al } 2008 \\
{[25]}\end{array}$ & $\begin{array}{l}\text { Soft tissue forma- } \\
\text { tion }\end{array}$ & $\begin{array}{l}\text { Intrinsic he- } \\
\text { mangioma }\end{array}$ & Yes & NA & NA & NA & NA & NA \\
\hline $\begin{array}{l}\text { Kim et al } 2010 \\
{[26]}\end{array}$ & $\begin{array}{l}\text { Intraneural he- } \\
\text { mangioma }\end{array}$ & Hemangiomas & Yes & NA & $\begin{array}{l}\text { Heterogene- } \\
\text { ous }\end{array}$ & $\begin{array}{l}\text { Slightly } \\
\text { increased }\end{array}$ & NA & NA \\
\hline $\begin{array}{l}\text { Reddy et al } 2013 \\
\text { [30] }\end{array}$ & NA & $\begin{array}{l}\text { Capillary } \\
\text { hemangioma }\end{array}$ & Yes & Well defined & Нypo-echoic & Yes & Increased & NA \\
\hline $\begin{array}{l}\text { Jafari et al } 2015 \\
\text { [34] }\end{array}$ & $\begin{array}{l}\text { Hamartoma and } \\
\text { other perineural } \\
\text { masses }\end{array}$ & $\begin{array}{l}\text { Cavernous } \\
\text { hemangioma }\end{array}$ & Yes & NA & Нypo-echoic & NA & $\begin{array}{l}\text { No signifi- } \\
\text { cant }\end{array}$ & NA \\
\hline $\begin{array}{l}\text { González Porto et } \\
\text { al } 2016 \text { [35] }\end{array}$ & $\begin{array}{l}\text { Venous Malfor- } \\
\text { mation }\end{array}$ & $\begin{array}{l}\text { Venous Mal- } \\
\text { formation }\end{array}$ & No & $\begin{array}{l}\text { Irregularly } \\
\text { shaped space }\end{array}$ & NA & Yes & Low level & NA \\
\hline $\begin{array}{l}\text { Our case no } 1 \\
2018\end{array}$ & $\begin{array}{l}\text { Venous Malfor- } \\
\text { mation }\end{array}$ & $\begin{array}{l}\text { Venous Mal- } \\
\text { formation }\end{array}$ & No & $\begin{array}{l}\text { Irregularly } \\
\text { shaped space }\end{array}$ & Нypo-echoic & Yes & Low level & $\begin{array}{l}\text { Mono- } \\
\text { phasic }\end{array}$ \\
\hline $\begin{array}{l}\text { Our case no } 2 \\
2018\end{array}$ & $\begin{array}{l}\text { Arterio-Venous } \\
\text { Malformation }\end{array}$ & $\begin{array}{l}\text { Arterio-Ve- } \\
\text { nous Malfor- } \\
\text { mation }\end{array}$ & No & $\begin{array}{l}\text { Irregularly } \\
\text { shaped space }\end{array}$ & Нypo-echoic & Yes & Increased & Yes \\
\hline
\end{tabular}

AVM - arteriovenous malformation; NA - not available 


\section{Discussions}

Vascular anomalies are a type of disease commonly found in the skin, soft tissues, bones, liver, spleen, and central nervous system. They are the result of a defective vascular development, with impaired number, size and course, usually appearing as numerous, dilated, tortuous vessels. They may appear either during intrauterine development or postpartum, each subtype of anomaly observing an own, typical pattern of development.

In 1982, Mulliken and Glowacki [43] published a classification of vascular abnormalities that divided them into hemangiomas (subclassified as proliferative phase and involutional phase hemangiomas) and vascular malformations (venous, lymphatic, capillary, arterial, fistula). This classification was based on etiology, clinical observations, model of endothelial proliferation, cell morphology, and histology.

In 1996, the International Society for the Study of Vascular Anomalies (ISSVA) published a wider and more complex classification, the latest update of it dating back to 2014 [2]. According to the ISSVA classification, vascular abnormalities include vascular tumors and vascular malformations.

Vascular tumors are tissues containing neoplastic endothelial proliferation, including a soft tissue component (collagenous stroma) and a vascular component (vascular channels). These tumors may be benign, locally aggressive or malignant, and include infantile hemangioma, the most common vascular tumor, but also rare entities, such as congenital hemangioma - with two subgroups: non-evolutive (NICH - Non Involuting Congenital Hemangioma), respectively rapidly evolutive (RICH - Rapidly Involuting Congenital Hemangioma) - kaposiform hemangioendothelioma (KHE), piogenic granuloma and angiosarcoma [43-46].

Vascular proliferation is subdivided on the basis of the presence or absence of the endothelial cellular glucose transporter (GLUT). Infantile hemangiomas and angiosarcomas contain the GLUT1 protein (they are GLUT $1+$ ), while congenital hemangiomas and kaposiform hemangioendotheliomas do not contain this protein (they are GLUT 1-) [45].

Vascular malformations represent abnormal development of the vessels, with the preservation of a stable endothelial pattern. In terms of the vessel type involved, these defects can be simple, with an involvement of a single type of vessel - arterial, venous, lymphatic, or capillary - or combined.

Flow velocity permits the classification of these anomalies into fast flow and slow flow abnormalities. Fast flow abnormalities include vascular tumors, arterial malformations, arteriovenous malformations, and arteriovenous fistulae. Slow flow abnormalities include venous, capillary and lymphatic malformations [42].

Despite the proposed systems for distinguishing between proliferative and dysplastic vascular abnormalities, inconsistencies still persist between the radiological [39] and histopathological classification of vascular lesions [43-46]. Abnormal vascular development may induce hard to diagnose and classify lesions in organs such as the breast [47].

Vascular abnormalities with intrinsic peripheral nerve development are of extremely rare occurrence.

Prassad et al [31] proposed an accurate anatomical classification, based on the compartmental delimitation of intraneural vascular abnormalities, according to their relationship with neural connective tissues: paraneurium and epineurium. Intraneural lesions were classified in sub-paraneurial - with normal nerve diameter and without changes of the sub-epineurial component - and sub-epineurial, with nerve thickening and T2 hypersignal. Lesions outside the epineurium, which did not follow the anatomical course of the nerve, were classified as extraneural.

Little is known about the very rarely occurring peripheral intraneural vascular anomalies. The cases presented in this work suggest that the presence of symptoms and signs attributable to peripheral nerve ailment in a patient with simultaneous regional vascular anomaly might indicate neural involvement. US is an excellent tool for direct visualization of most of the peripheral nerves and has the ability to depict neural involvement and to analyze intraneural flow noninvasively. The extent of the lesions in our cases suggested neural involvement through the vasa nervorum. In one of the cases we even observed progression of the disease to a second nerve, as local conditions remained basically unchanged.

Inconsistencies in classification and reporting made the aggregation of the reviewed data difficult.

Surprisingly, most of the reviewed cases were explored with MRI, with very few US reports, in spite of its obvious advantages. In our cases, US directly depicted the intraneural location of the abnormal vessels and it allowed for flow analysis, thus leading to accurate classification of the anomalies. The therapeutic strategy was revised based on US findings. Sonography also represented an extremely useful tool for follow-up, depicting, in one case, progression of the disease to a second nerve of the same segment, this being, to the best of ourknowledge, the first report of this kind.

\section{Conclusions}

Our review suggests that peripheral intraneural vascular anomalies are twice more frequent in women. 
About three quarters of them are located in the upper limb, with the median nerve involved in one third and the ulnar nerved involved in a quarter of all cases. Most of the cases are hemangiomas, the other types of vascular abnormalities being of singular occurrence. Peripheral neural compartment syndromes in patients with coexisting vascular anomalies may prompt for vascular neural involvement, requiring diagnostic imaging studies.

Noninvasive imaging such as ultrasound and magnetic resonance imaging provides paramount information on the morphology, flow characteristics, anatomical relationships and differential diagnosis in these patients, with relevant information for treatment decision making. Gray-scale and Doppler ultrasound are the methods of first choice, as they provide not only direct visual proof of neural involvement but also contribute to the differential diagnosis between hemangiomas and vascular malformations. Contrast enhanced magnetic resonance imaging may serve to complete the diagnosis.

Conflicts of interests: none.

\section{References}

1. Greene AK. Vascular anomalies: current overview of the field. Clin Plast Surg 2011;38:1-5.

2. International Society for the Study of Vascular Anomalies. ISSVA Classification of Vascular Anomalies (C2014. Available at: http://www.issva.org/classification. Accessed: 25.06.2017.

3. Kojima T, Ide Y, Marumo E, Ishikawa E, Yamoshita H. Hemangioma of median nerve causing carpal tunnel syndrome. Hand 1976;8:62-65.

4. Chopra JS, Khanna SK, Murthy JM. Congenital arteriovenous fistula producing carpal tunnel syndrome. J Neurol Neurosurg Psychiatry 1979;42:815-817.

5. Wood MB. Intraneural hemangioma: report of a case. Plast Reconstr Surg 1980;65:74-76.

6. Peled I, Iosipovich Z, Rousso M, Wexler MR. Hemangioma of the median nerve. J Hand Surg Am 1980;5:363-365.

7. Kon M, Vuursteen PJ. An intraneural hemangioma of a digital nerve - case report. J Hand Surg Am 1980;6:357-358.

8. Louis DS, Hankin FM. Benign nerve tumors of the upper extremity. Bull N Y Acad Med 1985;61:611-620.

9. Patel CB, Tsai TM, Kleinert HE. Hemangioma of the median nerve: a report of two cases. J Hand Surg Am 1986;11:76-79.

10. Prosser AJ, Burke FD. Haemangioma of the median nerve associated with Raynaud's phenomenon. J Hand Surg Br 1987; 12:227-228.

11. Bilge T, Kaya A, Alatli M, Bilge S, Alatli C. Hemangioma of the peroneal nerve:case report andreview of the literature. Neurosurgery 1989;25:649-652.
12. Nagay L, McCabe SJ, Wolff TW. Haemangioma of the digital nerve: a case report. J Hand Surg Br 1990;15:487488.

13. Feyerabend T, Schmitt R, Lanz U, Warmuth-Metz M. CT morphology of benign median nerve tumors. Report of three cases and a review. Acta Radiol 1990;31:23-25.

14. Mestdagh H, Lecomte-Houcke M, Reyford H. Intraneural haemangiome of the posterior tibial nerve. J Bone Joint Surg Br 1990;72:323-324.

15. Coessens B, De Mey A, Lacotte B, Vandenbroeck D. Carpal tunnel syndrome due to an haemangioma of the median nerve in a 12-year-old child. Ann Chir Main Memb Super 1991;10:255-257.

16. Kline SC, Moore JR. Intraneural hemangioma: a case report of acute cubital tunnel syndrome. J Hand Surg Am 1992;17:305-307.

17. Kon M, Schellekens PPA. Intraneural hemangioma of the ulnar nerve at the wrist. Eur J Plastic Surg 1993;16:242244.

18. Ergin MT, Druckmiller WH, Cohen P. Intrinsic hemangiomas of the peripheral nerves report of a case and review of the literature. Conn Med 1998;62:209-213.

19. Kim DH, , Murovic JA, Tiel RL, Moes G, Kline DG. A series of 146 peripheral non-neural sheath nerve tumors: 30-year experience at Louisiana State University Health Sciences Center. J Neurosurg 2005;102:256-266.

20. Kerimoglu U, Uzumcugil A, Yilmaz G, Ayvaz M, Leblebicioglu G, Altinok G. Intraneural hemangioma of digital nerve diagnosed with MR imaging. Skeletal Radiol 2007;36:157-160.

21. Galea LA, Conte F. Digital vascular malformation originating from the vasanervorum of the digital nerve. J Plast Reconstr Aesthet Surg 2007;60:1077-1078.

22. Chatillon CE, Guiot MC, Jacques L. Lipomatous, vascular, and chondromatous benign tumors of the periphal nerves: representative cases and review of the literature. Neurosurg Focus 2007;22:E18.

23. Papagelopoulos PJ, Mavrogenis AF, Skarpidi E, Nikolaou I, Soucacos PN. A 56-year-old woman with a right arm mass. Clin Orthop Relat Res 2008;466:2892-2898.

24. Doğramacı Y, Kalacı A, Sevinç TT, Yanat AN. Intraneural hemangioma of the median nerve: A case report. J Brachial Plex Peripher Nerve Inj 2008;3:5.

25. Vekris MD, Stafilas KS, Zacharis KX, Xenakis TA, Soucacos PN, Beris AE. Intrinsic haemangioma of the median nerve: report of a case and review of the literature. Microsurgery 2008;28:89-90.

26. Kim DH, Kang JW, Park JW. Multilevel ulnar neuropathy caused by multiple intraneural hemangiomas. Muscle Nerve 2010;41:562-566.

27. Van Gompel JJ, Griessenauer CJ, Scheithauer BW, Amrami KK, Spinner RJ. Vascular malformations, rare causes of sciatic neuropathy: a case series. Neurosurgery 2010;67:11331142.

28. Hariri A, Cohen G, Masmejean EH. Venous malformation involving median nerve causing acute carpal tunnel syndrome. J Hand Surg Eur Vol 2011;36:431-432. 
29. Düzgün S, Ozdemir A, Unlü E, Pekdemir I, Yılancı S, Alhan B. The intraneural hemangioma of the digital nerve: case report. J Hand Microsurg 2013; 5:27-29.

30. Reddy YM, Meena AK, Uppin MS, Vadapalli R, Challa S. Intraneural capillary hemangioma: a rare cause of proximal median neuropathy. Neurol India 2013;61:660-662.

31. Prasad NK, Chawla A, Lalezari S, et al. A radiological classification system for intraneural vascular anomalies: assessment of potential for resection with high-resolution MRI. Acta Neurochir 2016;158:329-334.

32. Rousié M, Ledoux P. Intraneural hemangioma: A rare cause of intermittent carpal tunnel syndrome. Chir Main 2015;34:322-323.

33. Prasad NK, Capek S, Ruiter GC, Amrami KK, Spinner RJ. The subparaneurial compartment: A new concept in the clinicoanatomic classification of peripheral nerve lesions. Clin Anat 2015;28:925-930.

34. Jafari D, Shariatzade H, Najd-mazhar F, Razavipour M. Intraneural cavernous haemangioma of ulnar nerve and cubital tunnel syndrome. Comp Clin Pathol 2015;24:957-959.

35. González Porto SA, González Rodríguez A, Midón Míguez J. Intraneural Venous Malformations of the Median Nerve. Arch Plast Surg 2016;43:371-373.

36. Prater MC, Janz BA. Mixed Lymphangioma and Cavernous Hemangioma Within the Ulnar Nerve: A Case Report. Hand 2017;12:NP145-NP147.

37. Al-Garnawee M, Najjar MW. Median Nerve Cavernous Hemangioma. Basic Clin Neurosci 2017;8:255-259.

38. Vilanova JC, Barcelo J, Smirniotopoulos JG, et al. Hemangioma from head to toe: MR imaging with pathologic correlation. Radiographics 2004;24:367-385.
39. Lowe LH, Marchant TC, Rivard DC, Scherbel AJ. Vascular malformations: classification and terminology the radiologist needs to know. Semin Roentgenol 2012;47:106117.

40. Behr GG, Johnson CM. Vascular Anomalies: Hemangiomas and Beyond-Part 2, Slow-Flow Lesions. AJR Am J Roentgenol 2013;200:423-436.

41. Ranalli NJ, Huang JH, Lee EB, Zhang PJ, Siegelman ES, Zager EL. Hemangiomas of the Brachial Plexus: A Case Series. Neurosurgery 2009;65:A181-A188.

42. Flors L, Leiva-Salinas C, Maged IM, et al. MR imaging of soft-tissue vascular malformations: diagnosis, classification, and therapy follow-up. Radiographics 2011;;31:13211340 .

43. Mulliken JB, Glowacki J. Hemangiomas and vascular malformations in infants and children: a classification based on endothelial characteristics. Plast Reconstr Surg 1982;69:412-422.

44. Adegboyega PA, Qiu S. Hemangioma versus vascular malformation: presence of nerve bundle is a diagnostic clue for vascular malformation. Arch Pathol Lab Med 2005; 129:772-775.

45. Behr GG, Johnson C. Vascular anomalies: hemangiomas and beyond-part 1, Fast-Flow lesions. AJR Am J Roentgenol 2013;200:414-422.

46. Hassanein AH, Mulliken JB, Fishman SJ, Greene AK. Evaluation of terminology for vascular anomalies in current literature. Plast Reconstr Surg 2011;127:347-351.

47. Ciurea A, Dudea SM, Lebovici A, Fodor L, Crisan D. Diffuse angiomatosis of the breast-sonographic appearance. $\mathrm{J}$ Clin Ultrasound 2014;42:498-501. 